\title{
Solid Solubility Metastable Extension of Rare Earth Metals in Gold
}

\author{
Zhou Xinming and Li Qubo \\ Institule of Precious Metals, Kunming, Yunnan, 650221, China
}

\begin{abstract}
Metastable extended solid solubility of rare earth (RE) metals in gold was studied by measuring the lattice parameters of solid solutions of rapidly solidified Au-RE alloys using X-ray diffraction. The cooling rate used for the preparation of the alloys was about $10^{6} \mathrm{~K} / \mathrm{s}$. It was found that the metastable solid solubilities of $\mathrm{Ce}, \mathrm{Sm}, \mathrm{Gd}, \mathrm{Dy}, \mathrm{Er}, \mathrm{Yb}$ and $\mathrm{Y}$ in gold were $0.3,0.4,1.5,9.0,13,13.4$ and 10 at $\%$ respectively. The solid solubilities of $\mathrm{RE}$ metals in gold increased with decreasing relative difference of atomic radius between the $\mathrm{RE}$ metal and gold. The extended solid solubilities of RE metals in $\mathrm{Au}, \mathrm{Ag}$, and $\mathrm{Cu}$ were compared. The relatively large solid solubility in gold is explained in terms of electron transfer from the RE atoms to gold atoms. Under the conditions of rapid solidification, the Au-RE alloys tended to form amorphous alloys more readily than do Ag-RE alloys.
\end{abstract}

The formation of solid solutions is an important aspect of alloying theory. The Hume-Rothery, Darken and Gurry and other groups have reported significant work on the prediction of solid solubility in alloys. The basic empirical rules governing the formation of solid solution alloys are:

(1) The $15 \%$ size rule: This states that solid solutions are not to be expected if the atomic size of the solvent and solute differ by more than $15 \%$.

(2) The electrochemical factor: The electrochemical nature of the two elements must be similar. If their electrochemical properties are significantly different, compound formation is more likely. Darken and Gurry made use of the electronegativity to quantify the electrochemical factor - if the electronegativity difference between solvent and solute is more than +0.4 , large solid solubility is not to be expected.

In the 1960s, Duwez developed the technique of rapid solidification and found it was associated with three major effects, ie the extension of solute solubility, the formation of metastable phases, and the formation of metallic glasses (amorphous alloys).

The extension of solute solubility is potentially perhaps the most significant of these effects. Not only does its study increase our understanding of the interactions between alloy constituents but it also offers a new approach to the development of alloys with solid solution hardening or age-strengthening properties. It is therefore of considerable practical significance.

The authors have previously systematically studied the extension of the solid solubility of rare earth (RE) mctals in silver, copper and aluminium (1 - 3). In this paper, the metastable extension of solid solubility of rare carth metals in gold by rapid solidification is described.

\section{EXPERIMENTAL}

The alloys used in the present work were prepared from high (99.999\%)purity gold and pure (99.9\%) rare carth mctals ( $\mathrm{RE}=\mathrm{Ce}, \mathrm{Sm}, \mathrm{Gd}, \mathrm{Dy}, \mathrm{Er}, \mathrm{Yb}, \mathrm{Y}$ ). The alloys were first melted in a boron nitride crucible under an argon atmosphere using a high frequency induction current. Then a small piece of the alloy was re-melted and made into thin foils of thickness 0.03$0.05 \mathrm{~mm}$ by an AMHA-2 arc melting hammer-anvil installation, made in-house. For the process of remelting and making the foils, the equipment was first pumped to vacuum and then filled with high purity argon. The cooling rate for the rapid solidification of the Au-RE alloy foils was of the order of $10^{6} \mathrm{~K} / \mathrm{s}$.

For selected Au-RE, foils, chemical analysis was performed by inductively coupled plasma atomic 
emission spectroscopy. Analytical results indicated that the actual composition was quite close to the nominal composition because loss of RE by vaporization had becn taken into consideration. The listed compositions have been corrected in accordance with the analytical results.

The metastable extension of the solid solubility limit of the rare earth metal in gold was determined by measuring the lattice parameters of gold-rich solid solutions of rapidly solidified alloy, and verified by transmission electron microscopy (IEM), if necessary. The lattice parameters of gold-rich solid solutions were measured by $\mathrm{X}$-ray diffraction using $\mathrm{Cu} \mathrm{K} \alpha \mathrm{l}$ radiation with a $\mathrm{D} / \mathrm{max}-12 \mathrm{~K}$ diffractometer. 'The positions of the diffraction peaks were corrected using $99.999 \%$ high purity gold. The latrice parameters were calculated on a computer using the least-squares method. These measurements indicated that the method used had high precision. The TEM used was the JEM-2000EX model.

\section{RESULTS AND DISCUSSION}

The lattice parameters of solid solutions change almost linearly with solute concentration. When the solute concentration goes beyond the solid solubility limit, a second phase will appear in the alloy but the lattice parameters of the solid solution remain constant. From the relationship between the lattice parameters and the alloy compositions, and the accompanying TEM observations, the metastable extended solid solubilities of RE in gold in alloys obtained using rapid solidification can be determined.

The lattice parameters of gold-light RE solid solutions had no obvious increase with the increasing RE concentration in alloys under rapid solidification. The results indicated that the extension of solid solubility of light rare earths $(\mathrm{RE}=\mathrm{Ce}, \mathrm{Sm})$ in gold by rapid solidification was negligible. Rider et al (4) studied the solid solubilities of the rare earths in gold. 'They attempted to estimate the solid solubility limits of light rare earths in gold from the slopes of the lattice parameter vs composition curves in the single-phase region for gold-heavy $R E$ alloys plotted against the radii of RE metals. Using the same method, we determined the metastable extended solid solubilities for $\mathrm{Ce}$ and $\mathrm{Sm}$ in gold, which were found to be 0.3 and 0.4 at $\%$ respectively. The dependence of the lattice parameters of gold-rich solid solutions on $\mathrm{RE}$ concentration in rapidly solidified Au-RE ( $R E=\mathrm{Cd}, \mathrm{Dy}, \mathrm{Er}, \mathrm{Yb}, \mathrm{Y}$ ) alloys is shown in Figure 1. The extended solid solubilities of $\mathrm{Gd}, \mathrm{Dy}, \mathrm{Er}, \mathrm{Yb}$ and $\mathrm{Y}$ in gold were found to be 1.5, 9.0, $13,13.4$ and 10 at $\%$ respectively.

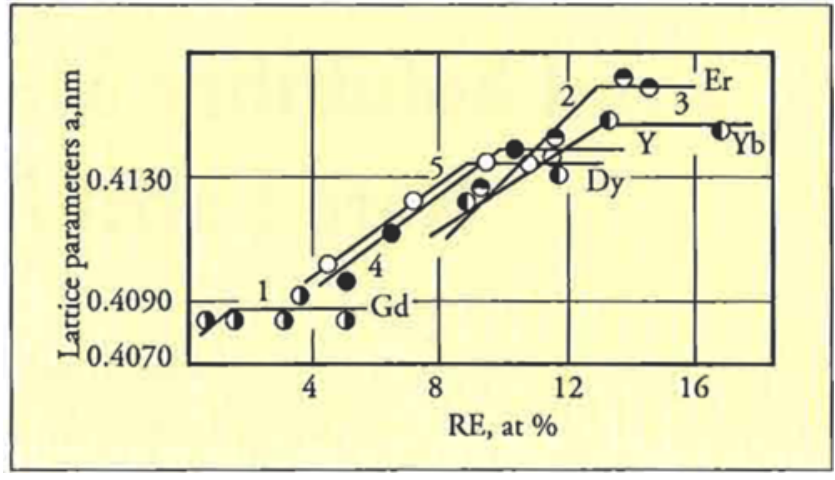

Figure 1 Lattice parameters of Au-rich solid solution vs $R E$ concentration in rapidly solidified $A u-R E$ $(R E=G d, D y, E r, Y b, Y)$ alloys

The atomic radius and electronegativity differences between rare earth metals and gold are quite large; the relative atomic radius difference is about $20-30 \%$, and the electronegativity difference is about 0.7 unit. These differences are unfavourable for the formation of solid solutions between rare earth metals and gold according to Hume-Rothery or Darken and Gurry criteria. But, in fact, the equilibrium and metastable extended solid solubilities $\left(\mathrm{C}_{\mathrm{en}}\right.$ and $\left.\mathrm{C}_{\mathrm{s}}^{*}\right)$ of some rare earth metals in gold are quite large. In Figure 2 the values for $C_{e q}$ and

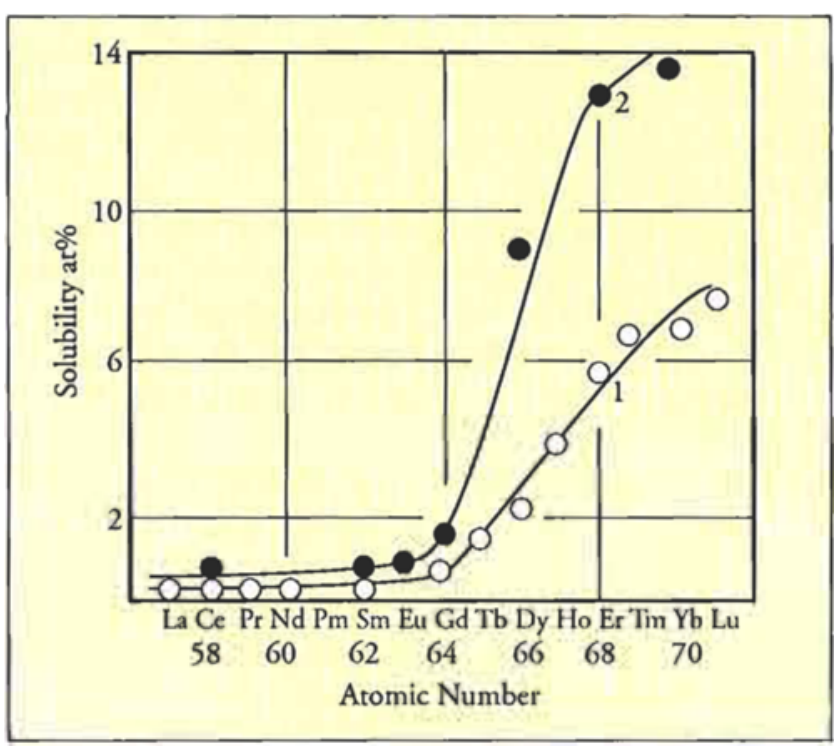

Figure 2 The maximum solid solubilities $C_{e q}$ (curve 1) and $C_{s}$ (curve 2) of the lanthanide metals in gold vs the lanthanide atomic number (the value of $C_{e q}$ is taken from (4))

\footnotetext{
* $C_{\text {rq }}$ is the maximun solid solubility, slow cooled (equilibrated) alloy; and $\mathrm{C}_{\mathrm{s}}$ is the maximum (extended) solid solubility in rapidly cooled (metastable) alloy.
} 
Table 1 Apparent atomic radii and solid solubilities of RE metals in gold

$\begin{array}{cc}\text { RE metal } & \begin{array}{c}\text { Apparent atomic } \\ \text { radii } \\ \mathbf{r a . a . r} \mathbf{n m}\end{array} \\ \mathrm{Yb} & 0.1619 \\ \mathrm{Er} & 0.1656 \\ \mathrm{Dy} & 0.1712 \\ \mathrm{Gd} & 0.1772\end{array}$

$\mathrm{C}_{s}$ of the lanthanide metals in gold are plotted against atomic numbers. The $\mathrm{C}_{\mathrm{eq}}$ and $\mathrm{C}_{s}$ values for the rare earths studied are plotted versus their relative radius differences in Figure 3. It can be seen that both $\mathrm{C}_{\text {eq }}$ and $\mathrm{C}_{s}$ increase with the increasing lanthanide atomic number or the contracting lanthanide atomic radius. The increases were very limited before Gd, but then increased approximately linearly with the decreasing of the relative atomic radius difference.

Rider et al (4) considered that upon alloying gold with rare earths, electron transfer from rare earth metals to gold occurred in the alloys, and that this would decrease the size of RE atom, and would increase its electronegativity. Conversely, it would increase the size of the gold atom and decrease its electronegativity. These changes in their electronic structures made the formation of solid solutions more favourable. Rider also considered that when the size difference between the constituent metal atoms was too large $(>25 \%)$, such electron transfer would not occur. The authors consider that this explanation is reasonable. The apparent atomic radii $\left(r_{\text {a.a.r. }}\right)$ of the rare earth metals in gold were derived by extrapolation of the graph of lattice constant of gold-rich solid solution us composition to $100 \%$ rare earth metals. The apparent atomic radii of the rare earth metals in goldrich solid solutions were smaller than the accepted atomic radii in the pure state, see Table 1 . The relative difference between the $r_{\text {a.a.r }}$ of some heavy rare earth metals and $\mathrm{r}_{\text {Au }}$ was already less than $15 \%$. From Figures 2 and 3 , it can be seen that the bchaviour is distinctly different after the relative size difference achieved a certain critical value (about $25 \%$ ). Both the equilibrium solid solubility $\mathrm{C}_{\mathrm{eq}}$ and the metastable extended solid solubility $\mathrm{C}_{s}$ increased fast with the decreasing of the relative difference of the atomic radius. There was no obvious relationship between the solid solubility and atomic size difference if the relative difference of atomic radius exceeded some critical

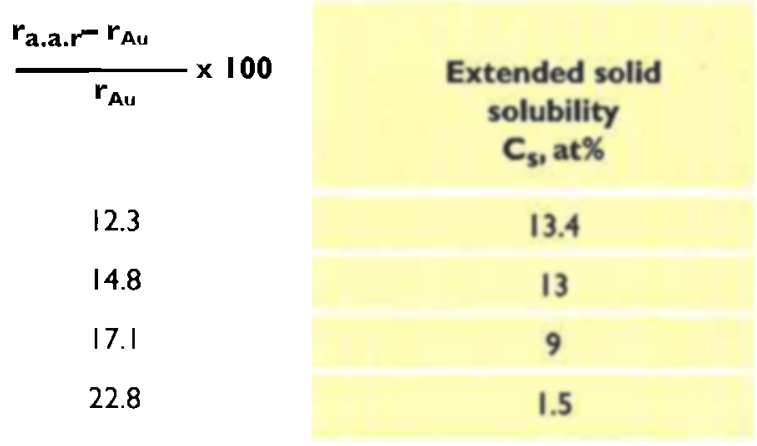

value. So the electron transfer that would favour the formation of solid solution occurred in gold-RE alloys only if the relative difference of atomic radius was smaller than the critical value. This opinion is in accord with the experimental values for the $\mathrm{C}_{\mathrm{cq}}$ and $\mathrm{C}_{\mathrm{s}}$ but its physical nature needs further research.

Ce, Sm and Gd have large atomic radii, and their extended solid solubilities in gold under rapid solidification are small. But we found that if their concentration exceeded 15 at $\%$, these alloys showed a tendency to form amorphous material under melt quenching. The X-ray diffraction patterns of melt quenched Au-RE (RE = Ce, Sm, Gd) alloy foils showed that the diffraction peaks of the second phase compound disappeared, and were characteristic of typical amorphous alloy when RE concentrations were



Figure 3 The maximum solid solubilities $C_{\text {eq }}$ (curve 1 - see reference 4), $C_{\text {s }}$ (curve 2 ) of lanthanide metals in gold us their relative atomic radius differences 
more than 15 at $\%$. Figure 4 is the $\mathrm{X}$-ray diffraction pattern of pure gold, and low and high concentration Au-Sm alloys. In the Differential Scanning Calorimetry measurements on these alloy foils there was an obvious exothermic peak during the isochronous heating process. But the results of TEM observation and electron diffraction tests indicated that these rapidly solidified foils were mainly characteristic of crystalline alloy. These melt quenched alloys may be in a mixed state of crystal and non crystal. Johnson (5) had pointed out that Au-La alloys in certain concentration ranges could become amorphous alloy through melt quenching. Compared with Ag-RE alloys the Au-RE alloys thus showed a stronger tendency to become amorphous.

The authors have studied the metastable extension of solid solubility of rare earths in $\mathrm{Ag}, \mathrm{Cu}$ and $\mathrm{Al}(1$ 3 ). Results from this previous work and the present research are given in Table 2 . The atomic radii of $\mathrm{Au}$, $\mathrm{Ag}, \mathrm{Al}$ and $\mathrm{Cu}$ are $0.1442,0.1445,0.1432$ and 0.1278 $\mathrm{nm}$, respectively. The atomic radii of $\mathrm{Au}, \mathrm{Ag}$, and $\mathrm{Al}$ are nearly the same, and the electronegativity differences between gold and the rare earths are larger than those between the rare earths and Ag, Al. But the extended solid solubilities of the rare earths, especially the heavy rare earths, in gold, are larger than those in $\mathrm{Al}$ and Ag. From the relationship of the extended solid solubilities of the rare earths and their atomic numbers, the solid solubilities of $\mathrm{Eu}$ and $\mathrm{Yb}$ in $\mathrm{Ag}$ and

Table 2 Metastable extension (at\%) of the solid solubilities of RE metals in $A u, A g, A l$ and $C u$

$\begin{array}{ccccc}\begin{array}{c}\mathrm{RE} \\ \text { Metals }\end{array} & \text { in } \mathrm{Au} & \text { in } \mathbf{A g} & \text { in } \mathbf{A l} & \text { in } \mathrm{Cu} \\ \mathrm{Y} & 10 & 2 & 0.4 & - \\ \mathrm{La} & - & 1 & 0.15 & - \\ \mathrm{Ce} & 0.3 & 1.5 & 0.21 & - \\ \mathrm{Pr} & - & 2.5 & 0.21 & - \\ \mathrm{Nd} & - & 3.0 & 0.30 & - \\ \mathrm{Sm} & 0.4 & 3.5 & 0.5 & 0.95 \\ \mathrm{Eu} & - & 0.3 & 0.1 & 0.5 \\ \mathrm{Gd} & 1.5 & 5.0 & 0.6 & 1.2 \\ \mathrm{~Tb} & - & 5.0 & 0.6 & 0.75 \\ \mathrm{Dy} & 9 & 5.4 & 0.7 & 1.0 \\ \mathrm{Er} & 13 & 6.0 & 0.75 & 0.9 \\ \mathrm{Yb} & 13.4 & 0.8 & 0.2 & 1.1\end{array}$

$\mathrm{Al}$ are obviously smaller than might be expected. This is because Eu and $\mathrm{Yb}$ showed divalent behaviour when they alloyed with $\mathrm{Ag}$ and $\mathrm{Al}$, and the difference of atomic radius was very large. But the solid solubilities (both $\mathrm{C}_{\mathrm{eq}}$ and $\mathrm{C}_{\mathrm{s}}$ ) of $\mathrm{Eu}$ and $\mathrm{Yb}$ in gold were normal, the solid solubilities of RE in gold changed regularly with the decreasing of the difference of atomic radius, see Figure 3, if the atomic radius of $\mathrm{Yb}$ is taken as the mean value of the lutetium and thulium atom radii. Eu and $\mathrm{Yb}$, in common with the other rare earth elements, showed trivalent behaviour in their alloys with gold. From the comparison of solid solubilities of the rare earths in $\mathrm{Au}, \mathrm{Ag}, \mathrm{Al}$, and the fact that $\mathrm{Eu}$ and $\mathrm{Yb}$ are trivalent in gold alloys, we considered that the electron transfer from RE atoms to gold atoms would be stronger than to $\mathrm{Ag}$ or $\mathrm{Al}$ atoms. This leads to larger solid solubility in gold, and the atomic size is the main factor controlling solid solubility when rare earths alloy with $\mathrm{Au}, \mathrm{Ag}$, or $\mathrm{Al}$. The atomic radius differences between $\mathrm{RE}$ and copper were in the range $35.8-54.7 \%$. This was too large, and was larger than the critical value (25\%) needed for electron transfer to occur. So when rare earths alloy with copper, the metastable extended solid

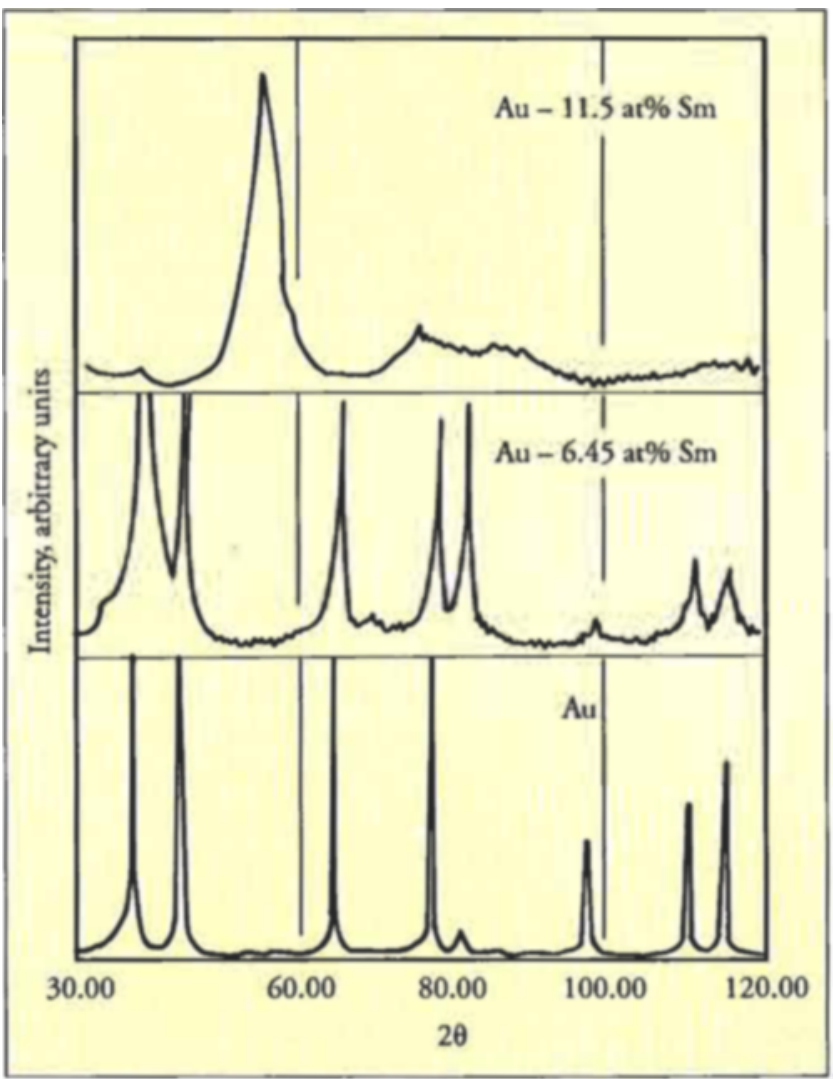

Figure $4 X$-ray diffraction patterns of rapidly solidified pure gold, and low and high concentration $A u$ Sm alloys 
solubilities are small, and there is no obvious relationship with the RE atomic size - in this case, the size is not the main factor influencing solid solubility. Other factors such as the characteristics of the copper-rich intermetallic compound which is formed and the eutectic temperatures, etc, became more important.

\section{CONCLUSIONS}

Under rapid solidification conditions, with a cooling rate of $10^{6} \mathrm{~K} / \mathrm{s}$, the metastable extended solid solubilities of $\mathrm{Ce}, \mathrm{Sm}, \mathrm{Gd}, \mathrm{Dy}, \mathrm{Er}, \mathrm{Yb}$ and $\mathrm{Y}$ in gold were $0.3,0.4$, $1.5,9.0,13,13.4$ and 10 at $\%$ respectively. The metastable extended solid solubilities of rare earths in gold were related to the relative atomic radius difference between the rare earth element and gold, and as a result, increased approximately linearly with the decrease of relative difference when the relative difference was less than $25 \%$. But there was no obvious relationship between the two if the relative difference was greater than the critical value (about $25 \%$ ).

The electron transfer from the rare earth metal to the gold was thought to occur when the RE alloyed with gold. The electron transfer was favourable for solid solution formation. But this transfer would not occur if the relative atomic radius difference was larger than the critical value. The extended solid solubilities of the rare earth in gold were larger than that in silver or aluminium. It was considered that the electron transfer from the rare earth to gold was stronger than that from the rare earth to silver or aluminium.

$\mathrm{Eu}$ and $\mathrm{Yb}$ showed divalent behaviour when they alloyed with $\mathrm{Ag}$ and $\mathrm{Al}$. The solid solubilities of $\mathrm{Eu}, \mathrm{Yb}$ in $\mathrm{Ag}$ and $\mathrm{Al}$ were distinctly smaller than those of the nearby rare earth elements. But as in the case of the other rare earths, $\mathrm{Eu}$ and $\mathrm{Yb}$ showed trivalent behaviour when they alloyed with Au. The solid solubilities of $\mathrm{Eu}$ and $\mathrm{Yb}$ in gold changed regularly with the relative atomic radius difference.

When rare earths alloy with $\mathrm{Au}, \mathrm{Ag}$ or $\mathrm{Al}$ and form solid solutions, their size is the main factor controlling their solid solubility. But when rare earths alloy with
$\mathrm{Cu}$ and form a solid solution, the importance of the size factor decreases, and other factors became more important.

Under rapid solidification conditions, the Au-RE alloys showed a stronger tendency to become amorphous than was the case for Ag-RE alloys.

\section{ACKNOWLEDGEMENTS}

The authors wish to express their appreciation to senior engineers Wang Zhongming and $\mathrm{Li}$ Shilin for their assistance in the X-ray diffraction and TEM analysis.

\section{ABOUT THE AUTHORS}

Professor Zhou Xinming is currently a Research Fellow in the Institute of Precious Metals, Kunming, Yunnan, China. He has made many original contributions in the field of precious metals alloy materials, including high purity gold alloys for the electronics industry. He has also carried out substantial research on metastable alloys.

Li Qubo is a member of Professor Zhou's research group. His recent research has been concerned with gold and gold alloys, including their use in the microelectronics industry.

\section{REFERENCES}

1 N. Yuantao, Z. Xinming and D. Hong, Chin. J. Met. Sci.Technol., 1991, 7, 391

2 Z. Xinming, N. Yuantao, and L. Qubo, J. Alloys and Compounds, 1992, 183, 168

3 N. Yuantao and Z. Xinming, Acta Metall Sin., 1992, 28, B95 (in Chinese)

4 P.E. Rider, K.A. Gschneider and O.D. McMasters, Trans. Met. Soc. AIME, 1965, 233, 1488

5 W.L. Johnson, S.J. Poon and P. Duwez, Phys. Rev., B, 1975, (11), 150 